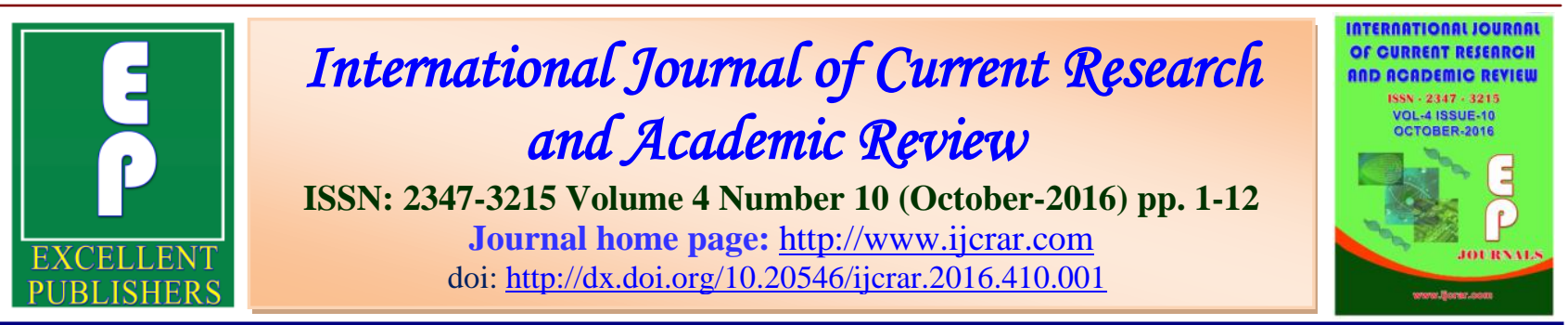

\title{
Depression in Patients with Rheumatoid Arthritis and its Relationship with Clinical and Demographic Variables in Golestan Hospital of Ahvaz, Iran
}

\author{
Masoumeh Nazarinasab ${ }^{1}$, Sirous Pakseresht ${ }^{1}$, Elham Rajai ${ }^{2}$ and Soroush Saneifard S,3* $^{*}$ \\ ${ }^{1}$ Department of Psychiatry, Golestan hospital, Ahvaz Jundishapur University of Medical \\ Sciences, Ahvaz, Iran \\ ${ }^{2}$ Department of Rheumatology, Ahvaz Jundishapur University of Medical Sciences, Ahvaz, \\ Iran \\ ${ }^{3}$ Student Research Committee, Ahvaz Jundishapur University of Medical Sciences, Ahvaz, \\ Iran
}

\section{KEYWORDS}

Depression, rheumatoid arthritis, chronic disease.

\section{A B S T R A C T}

Rheumatoid arthritis is the most common inflammatory rheumatic disease. Its prevalence is approximately $1 \%$ in most communities. The prevalence of the disease is estimated as $0.19 \%$ in urban areas and $33 \%$ in rural areas. Clinical consequences of rheumatoid arthritis are psychological and biological that the prevalence of depression is effective in worsening it. The aim of this study is to evaluate depression in patients with rheumatoid arthritis and its relationship with clinical and demographic variables in Golestan Hospital of Ahvaz. This study is a cross-sectional study. After obtaining informed consent 240 patients with rheumatoid arthritis selected by the rheumatologist according to ACR criteria in Golestan Hospital of Ahvaz who are aged above 18 and could read and write are included in the study. The research tools include two questionnaires. After filling out the questionnaires by the patients under study, the data are analyzed. The questionnaires included 1- Beck Depression Inventory and 2- demographic information questionnaire. Finally the data are analyzed by SPSS software. Prevalence of depression was 57\% among patients; ranking depression components showed that the highest rank is associated with changes in the sleep patterns and the lowest rank is associated with suicidal thoughts and finally the role of demographic variables is evaluated on the depression in patients. The results showed that the variables of gender, age and marital status do not play a role in the depression but the place of living, education, occupation and duration of the disease play a role in patients' depression. Since depression has the highest prevalence in patients with diploma, blue-collar jobs and those who live in rural areas, it is important to care about the importance of psychological training on quality of life and ways to deal with depression in chronic diseases among these communities to reduce depression in patients by increasing awareness and improve the quality of life of these patients. 


\section{Introduction}

Today depression is one of the most common psychiatric problems that may appear with or without underlying cause. Usually the prevalence of depression is associated with an underlying cause that is exacerbated by a chronic disease that the treatment of the underlying disease can cause depression treatment (Razavian et al., 2009). In fact, physical disorders affect the quality of life and lead to psychological problems such as depression and despair in people. One of the diseases that cause mental disorder is rheumatoid arthritis. Patients with rheumatoid arthritis due to pain, fatigue, restriction of movement and daily activity suffer from impairment in physical, social, psychological and emotional function that affect their quality of life (Cadena et al., 2003). Depression plays a role in the prevalence of disease and its continuity. People who are in the passive rheumatoid arthritis stage, in case of the lack of control in stress, loneliness and depression will cause the disease recurrence (Van lankveld et al., 2003). Rheumatoid arthritis is the most common inflammatory rheumatic disease (Antony et al., 2003). Its prevalence is approximately $1 \%$ in most communities. The prevalence of the disease is estimated as $0.19 \%$ in urban areas and $33 \%$ in rural areas (Fereydoun et al., 2009). Rheumatoid arthritis is am inflammatory, systemic, chronic, debilitating disease with unknown etiology that its major symptoms are joint related and include morning stiffness, joint swelling and joints deformation. On the other hand this disease has numerous extra-articular manifestations including anemia, fatigue, neuropathy and sjogren. Only a small fraction of people with rheumatoid arthritis are completely recovered and the rest of them will ha this disease with fluctuations forever (Venables, 2011). Developing this disease leads to disability in several ways (Bern Lowe et al.,
2004). In 33\% of cases the mechanism of the incidence of this disability is the symptoms. Other mechanisms of the disability include: unknown factors (in $41 \%$ of cases), factors other than rheumatoid arthritis, for example depression and psychological status of patients in $26 \%$ of cases. Rheumatoid arthritis clinical outcome includes two psychological and biological parts that the prevalence of depression is effective in worsening it (Neal Robert, 2009). The simultaneous prevalence with a chronic disease compared with the concurrent prevalence of two other chronic illnesses other than depression cause a greater reduction in the patient's health status. The likelihood of depression increases in patients with a chronic disease such as rheumatoid arthritis (Maloes et al., 2011). The prevalence of depression in the United States of America is between 5\% and $10 \%$ that this level is higher in patients with rheumatoid arthritis and in some articles the prevalence of depression in patients with rheumatoid arthritis is equal with the population (Covic et al., 2006). Rheumatoid arthritis is a debilitating disease due to the chronic course, peripheral joints involvement and systemic symptoms. Concurrent development of depression with an effect on biological consequences and the psychological consequences of rheumatoid arthritis is effective in the onset or exacerbation of disability of these patients (Abid rahmani, 2013). In fact, depression as an illness that is caused by another underlying disease is discussed seriously and causes diseases such as rheumatoid arthritis that cause mobility problems and limitations in patients are the most common and important diseases. Review and follow up on the treatment of depression in patients with rheumatoid arthritis is necessary and important that should be analyzed in separate locations and different conditions comparatively. The first and most important 
step in providing a guide in diagnosing depression in patients with rheumatoid arthritis is to determine the prevalence of depression. This is used in choosing the most accurate method used to screen the patients (Travis, 2008), it seems that the prevalence of depression in patients with rheumatoid arthritis is higher than the nonpatient population. Several studies have estimated the prevalence of depression in patients with rheumatoid arthritis $17-27 \%$. In these patients there is a cross-sectional association between depression, depression symptoms, functional impairment and poorer clinical status. This study is carried out based on these factors that present the importance of the relationship between depression and symptoms of rheumatoid arthritis.

\section{Materials and Methods}

This study is a cross-sectional study. After obtaining the permission from the Ethics Committee of the Ahvaz Jundishapur University of Medical Sciences and obtaining informed consent, 240 patients with rheumatoid arthritis selected by the rheumatologist according to ACR criteria in Golestan Hospital of Ahvaz who are aged above 18 and could read and write are included in the study. Exclusion criteria included drug abuse, the use of antidepressants, and history of mental illness, any uncontrolled illness such as diabetes and migraines and patients with grade 4 rheumatoid arthritis. The research tools include two questionnaires that after filling out the questionnaires by the patients under study, the data are analyzed. The questionnaires included 1- Beck Depression Inventory and 2- demographic information questionnaire. Beck Depression Inventory consists of 21 items related to different symptoms and the patient is asked to rank the symptoms based on a 4-point scale from
0 to 3. Questions are related to feelings of disability, failure, guilt, irritability, sleep disorder, and loss of appetite. It is a selfassessment test which requires 5 to 10 minutes to complete. In this research, scoring was carried out based on the following instructions: 0-14 for normal patients or patients with normal depression; 15-31 for patients with mild depression; 3247 for patients with moderate depression; and 48-63 for patients with severe depression (Jiang, 2014). At the end of collecting the questionnaires for descriptive statistics, statistical data on the distribution of the respondents, the demographic characteristics and other data are included in the questionnaire. Also the frequency distribution tables and statistical graphs are used to describe the data. In inferential statistics, the applied method is Kolmogorov-Smirnov test for normality of the data binomial nonparametric tests (ratio), Mann-Whitney and Kruskal-Wallis test is used to test the hypotheses and Friedman test in SPSS software is applied to rank the research components and thus the research hypotheses are tested.

\section{Results and Discussion}

The results of the present study indicate that $16.7 \%$ of the respondents are male $(n=40)$ and $82.1 \%$ of the respondents are female ( $n$ $=197) .15 .8 \%$ of the respondents are single $(n=38), 76.7 \%$ are married $(n=184), 2.1 \%$ are divorced $(\mathrm{n}=5)$ and $5.0 \%$ are widowed $(n=12)$. Also, 3.8\% $(n=9)$ of respondents are aged between 15 and 25, 19.6\% $(n=47)$ are aged between 25 and 35, 27.1\% $(\mathrm{n}=65)$ are aged between 35 and 45 and $48.3 \%$ are aged over 45 years. The respondents are divided into three groups in terms of education that $35.8 \%(\mathrm{n}=86)$ have below high school diploma, 38.3\% $(\mathrm{n}=92)$ high school diploma, $22.1 \% \quad(n=53)$ have bachelor's degree or higher. $19.6 \%(n=47)$ 
are blue collar employees, $16.7 \% \quad(n=40)$ self-employed, 5\% are retired and disabled $(n=12), 47.1 \%(n=113)$ are housekeeper and $2.9 \%(\mathrm{n}=7)$ are unemployed and $83.8 \%$ $(n=201)$ are urban citizens and $13.3 \%$ $(n=32)$ are rural citizens. In case of the duration of disease it was also observed that $58.8 \%(n=141)$ suffer from the disease for 1 to 5 years, $21.7 \%(n=52)$ have the disease for 5 to 10 years and $17.5 \%(n=42)$ suffer from the disease for over 10 years (Charts 17).

It is then observed that the comparison between the observed ratios reflect the fact that Prevalence of depression was $57 \%$ among patients. Of the 240 patients in this study, 135 patients $(57 \%)$ of them had depression such that 105 patients (43\%) without depression, 113 patients $(47.1 \%)$ had mild depression, 19 patients (7\%) moderate depression and 3 patients $(3 \%)$ had severe depression. Also, the results obtained for the role of gender on the patients' depression is higher than $5 \%$ thus there is no reason to reject the null hypothesis and thus the gender has no role to play on patients' depression. Also by analyzing the results it became clear that the patients who live in the rural areas have higher depression than the urban citizens. Also patients with high school diploma have the highest rate of depression and patients with a bachelor's or higher degree have the lowest rate of depression. It is also observed that the age group and marital status do not play a role in the depression of patients. Blue collar patients have the highest rate of depression and the employees have the lowest rate of depression. Finally, it is observed that patients with the disease duration of over 5 years have higher rate of depression than patients with the disease duration of 1 to 5 years. In general the result indicates that the prevalence of depression was 57\% among the patients and the ranking of the depression components showed that the highest rank is associated with patients' insomnia and the lowest rank is associated with the suicidal thoughts and finally the role of demographic variables on depression in patients are analyzed. The results showed that the variables of gender, age and marital status do not play a role in the depression but the variables of the place of living, education, occupation and duration of the disease play a role in patients' depression (Table 1 and 2 ).

Rheumatoid arthritis disease causes disability in several ways (18). In $33 \%$ of cases the mechanism of the incidence of this disability is the symptoms. Other mechanisms of the disability include: unknown factors (in $41 \%$ of cases), factors other than rheumatoid arthritis, for example depression and psychological status of patients and lack of education in $26 \%$ of cases. It is believed that cytokines IL-6 and IL-1 are increased in depression and they are associated with depression severity (Maes et $a l ., 1995)$. Also, some cytokines such as IL6 can also affect the Level of monoamines in the central nervous system and cause neuropsychiatric disorders. It has been observed that after taking the drugs by rheumatoid arthritic patients, the increase in cytokines lead to the development of mental disorders (Dunn et al., 1999). Also the increase in serum levels of IL-17 in these patients is associated with anxiety and depression. In fact, peripheral inflammation in rheumatoid arthritis affects the neurotransmitters' metabolism, neuroendocrine function and synaptic function as well as growth factor production and can change neural circuits and help to increase depression (Malemud et al., 2008). In addition, cytokines activate indoleamine2,3-dioxygenase (IDO) enzyme, as well as reducing the tryptophan (a precursor of serotonin) and finally the reduction in 
serotonin and creating a neurochemical process to increase depression. Depression results are multiple in RA and they are out of access. This disease has broad impacts on quality of life and indirect social costs. Depression exacerbates the RA adverse health outcomes and increases mortality, increased risk of myocardial infarction (MI), inability to work and the cost of health care (Ang et al., 2013; Scherrer et al., 2009; Lowe et al., 2004). This information is consistent with the studies of other researchers for example Simacha et al carried out a study titled the use of health questionnaire in relation to the quality of life of patients with rheumatoid arthritis. Research results have shown that the quality of life in patients with rheumatoid arthritis is at low and undesirable levels. Wolfe et al., found that depression increases the duration of rheumatoid arthritis and reduces the quality of life of these patients. The research results by Jakobsoon in patients with rheumatoid arthritis indicated that loneliness and depression affect quality of life and reduces the quality of life of patients with rheumatoid arthritis (Jakobsson et al., 2002). This study is carried out based on these factors that present the importance of the relationship between depression and symptoms of rheumatoid arthritis and in general as observed in the results section. In general, the results of analysis showed that Prevalence of depression is 57\% among patients. Classification of depression components showed that the highest rank of change is associated with the patients' sleep pattern and the lowest rank is associated with suicidal thoughts and finally the role of demographic variables on depression in patients is evaluated. The results showed that the variables of gender, age and marital status do not play a role in the level of depression but the variables place of living, education, occupation and duration of the disease play a role in depression in patients.

Table.1 Prioritizing components related to depression

\begin{tabular}{|c|c|c|c|c|c|}
\hline Rank & Components & $\begin{array}{c}\text { Mean } \\
\text { rank }\end{array}$ & Rank & Components & $\begin{array}{c}\text { Mean } \\
\text { rank }\end{array}$ \\
\hline $1^{\text {st }}$ & Insomnia & 15.5 & $11^{\text {th }}$ & $\begin{array}{c}\text { Self- } \\
\text { accusations }\end{array}$ & 10.88 \\
\hline $2^{\text {nd }}$ & Loss of energy & 13.14 & $12^{\text {th }}$ & Agitation & 10.88 \\
\hline $3^{\text {rd }}$ & Fatigue & 12.87 & $13^{\text {th }}$ & Worthlessness & 10.6 \\
\hline $4^{\text {th }}$ & Change in appetite & 12.57 & $14^{\text {th }}$ & $\begin{array}{c}\text { Sense of } \\
\text { failure }\end{array}$ & 10.11 \\
\hline $5^{\text {th }}$ & $\begin{array}{c}\text { Decreased sexual } \\
\text { interest }\end{array}$ & 12.49 & $15^{\text {th }}$ & Indecision & 9.83 \\
\hline $6^{\text {th }}$ & Discontent & 12.22 & $16^{\text {th }}$ & Irritability & 9.78 \\
\hline $7^{\text {th }}$ & Crying & 12.05 & $17^{\text {th }}$ & $\begin{array}{c}\text { Social } \\
\text { withdrawal }\end{array}$ & 9.54 \\
\hline $8^{\text {th }}$ & Pessimism & 11.8 & $18^{\text {th }}$ & Punishment & 9.27 \\
\hline $9^{\text {th }}$ & $\begin{array}{c}\text { Difficulty in } \\
\text { concentration }\end{array}$ & 11.55 & $19^{\text {th }}$ & Self-dislike & 9.16 \\
\hline & Sadness & 11.44 & $20^{\text {th }}$ & Guilt & 8.48 \\
\cline { 4 - 6 } & & & $21^{\text {st }}$ & $\begin{array}{c}\text { Suicidal } \\
\text { thoughts }\end{array}$ & 7.28 \\
\hline
\end{tabular}


Int.J.Curr.Res.Aca.Rev.2016; 4(10): 1-12

Table.2 Prevalence of Depression based on Age, Gender, Marital status, Education, Job, Location and Disease Duration

\begin{tabular}{|c|c|c|c|c|c|c|}
\hline Variable & Sub-Variable & $\begin{array}{c}\text { Without } \\
\text { Depression }\end{array}$ & $\begin{array}{l}\text { Mild } \\
\text { Depression }\end{array}$ & $\begin{array}{l}\text { Moderate } \\
\text { Depression }\end{array}$ & $\begin{array}{l}\text { Severe } \\
\text { Depression }\end{array}$ & $\begin{array}{c}\text { Without } \\
\text { Depression }\end{array}$ \\
\hline \multirow[t]{4}{*}{ Age } & $15-25$ & 3 & 3 & 3 & 0 & 9 \\
\hline & $25-35$ & 23 & 21 & 3 & 0 & 47 \\
\hline & $35-45$ & 28 & 33 & 2 & 2 & 65 \\
\hline & $>45$ & 49 & 55 & 11 & 1 & 116 \\
\hline \multirow[t]{2}{*}{ Gender } & Male & 24 & 15 & 3 & 1 & 43 \\
\hline & Female & 81 & 98 & 16 & 2 & 197 \\
\hline \multirow{4}{*}{$\begin{array}{l}\text { marital } \\
\text { status }\end{array}$} & Single & 19 & 14 & 5 & 0 & 38 \\
\hline & Married & 82 & 88 & 11 & 3 & 184 \\
\hline & divorced & 0 & 4 & 1 & 0 & 5 \\
\hline & Widow & 3 & 7 & 2 & 0 & 12 \\
\hline \multirow{3}{*}{ Education } & Under Diploma & 35 & 45 & 5 & 1 & 86 \\
\hline & Diploma & 32 & 47 & 11 & 2 & 92 \\
\hline & $\begin{array}{l}\text { Bachelor's } \\
\text { Degree or higher }\end{array}$ & 33 & 19 & 1 & 0 & 53 \\
\hline \multirow[t]{6}{*}{ Job } & white-collar & 26 & 20 & 1 & 0 & 47 \\
\hline & Blue-collar & 2 & 10 & 2 & 0 & 14 \\
\hline & Free & 26 & 12 & 2 & 0 & 40 \\
\hline & $\begin{array}{l}\text { Retired and } \\
\text { disabled }\end{array}$ & 4 & 6 & 2 & 0 & 12 \\
\hline & housewife & 41 & 60 & 9 & 3 & 113 \\
\hline & Unemployed & 2 & 4 & 1 & 0 & 7 \\
\hline \multirow[t]{2}{*}{ Location } & Urban & 91 & 95 & 13 & 2 & 201 \\
\hline & Rural & 11 & 14 & 6 & 1 & 32 \\
\hline \multirow{3}{*}{$\begin{array}{l}\text { Disease } \\
\text { Duration }\end{array}$} & $1-5$ & 72 & 62 & 6 & 1 & 141 \\
\hline & $5-10$ & 14 & 33 & 4 & 1 & 52 \\
\hline & $>10$ & 15 & 17 & 9 & 1 & 42 \\
\hline
\end{tabular}

Chart.1 Gender Status

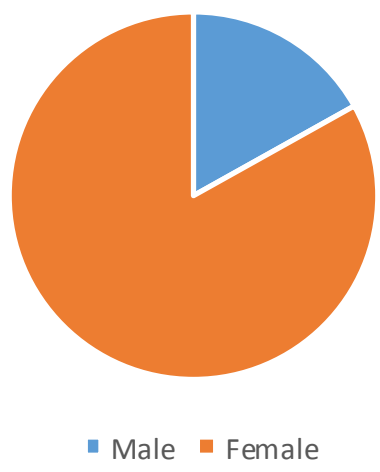


Int.J.Curr.Res.Aca.Rev.2016; 4(10): 1-12

Chart.2 Marital Status

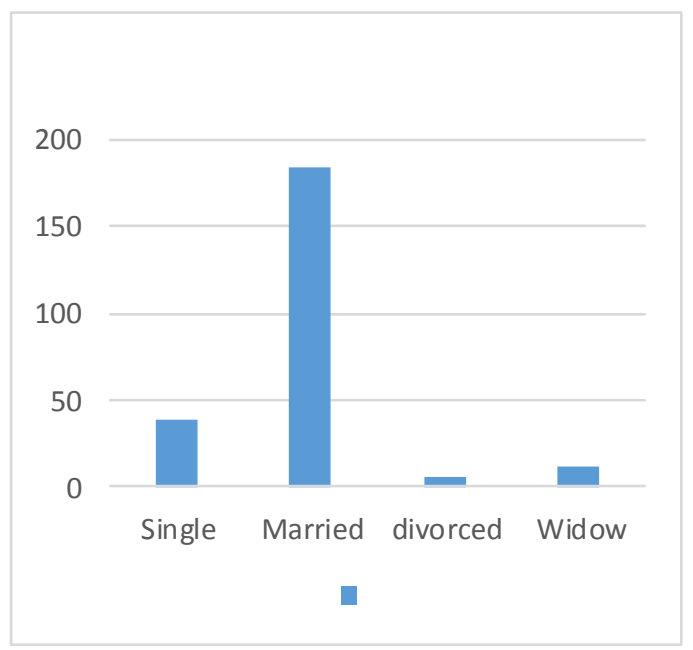

Chart.3 Education Status

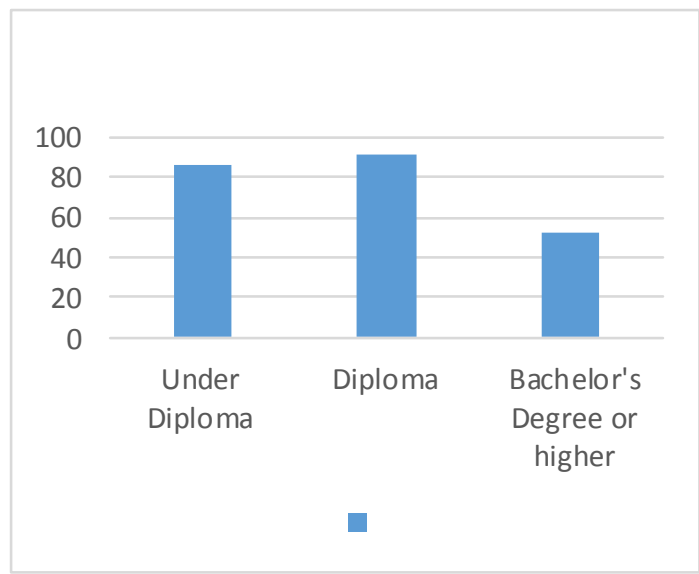

Chart.4 Age Status

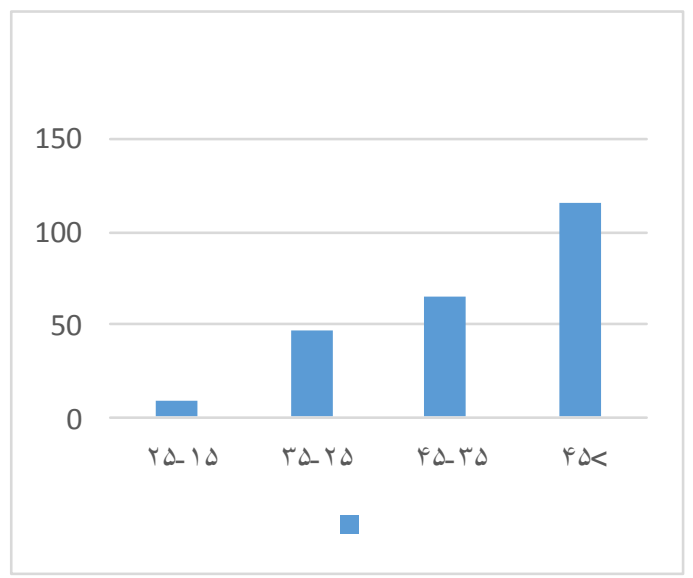


Int.J.Curr.Res.Aca.Rev.2016; 4(10): 1-12

Chart.5 Disease duration Status

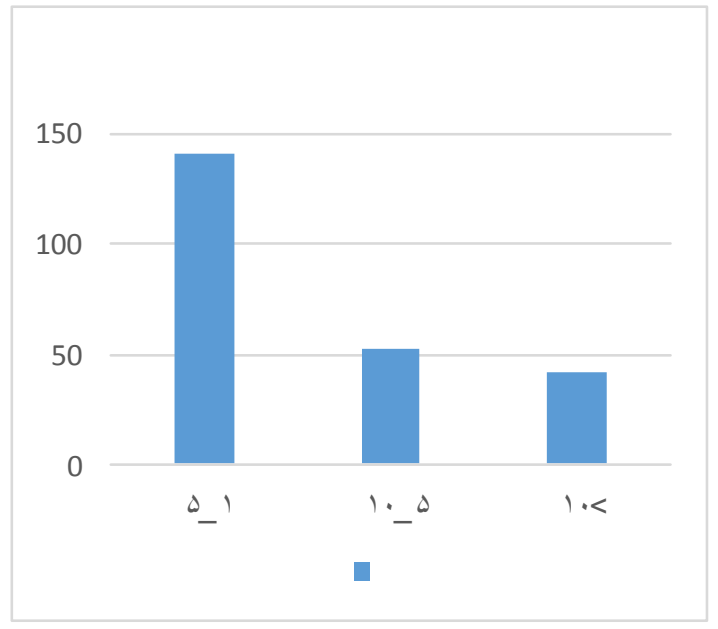

Chart.6 Location Status

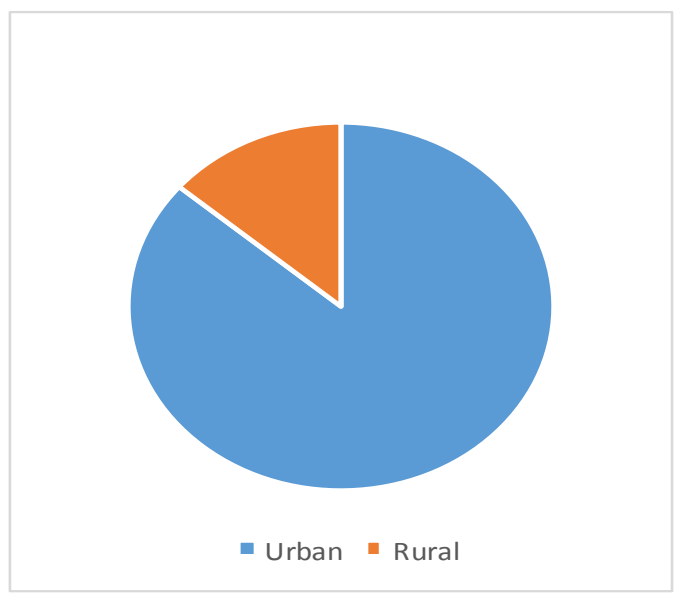

Chart.7 Job Status

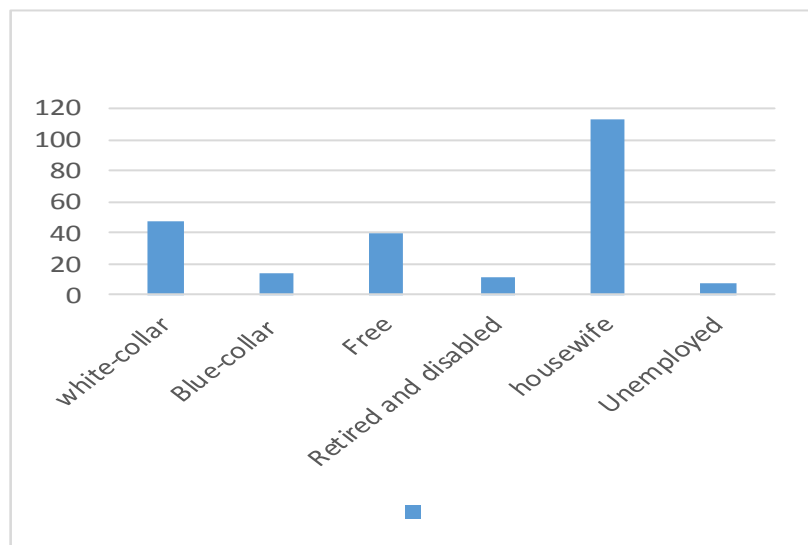

The review of the results of this study when compared with other studies could provide more effective to achieve the objectives of the research. In fact observing the statistically significant differences in the results of this study is the first step to further 
understanding of the condition of patients under study but to the notice the status of the patients and the improvement of the available patients versus other patients, it is necessary to compare the results with the results of other researchers. Many studies have focused on depression in patients with rheumatoid arthritis that a report if the studies and a comparison of their results are presented here. Ahmet et al., in a study titled "anxiety and depression in patients with rheumatoid arthritis" conducted on 82 subjects including 41 patients with rheumatoid arthritis and 41 healthy subjects as rge control in 2007 observed that anxiety and depression in particular were significantly higher in patients with rheumatoid arthritis (Ahmet et al., 2004). In another study conducted by Tillmann et al that included 637 patients with rheumatoid arthritis in London in 2013, it was observed that the severity of depression in patients with rheumatoid arthritis that their disease interferes with their daily activities was significantly higher. An interesting conclusion is obtained on the relationship between rheumatoid arthritis, depression and age of the patients in the 2013 by Najak et $a l .$, In this study that is conducted on 550 subject population, it was observed that $16 \%$ of patients with rheumatoid arthritis have progressive depression. In this study, it was observed that the relationship between rheumatoid arthritis and depression is higher among older patients that can be the basis for further research in this regard. Although the age variable is evaluated in the present study, no statistically significant data about the relationship between age and depression is found. In a study by Covic et al., conducted in Britain and Australia (Leeds and Sydney), the patients with rheumatoid arthritis were asked to fill the questionnaires about quality of life, depression and anxiety and the result of analyzing confirmed the relationship between rheumatoid arthritis, depression and anxiety in patients with rheumatoid arthritis in these two cities. In an article published by Margaretten Mary in 2013, the relationship between rheumatoid arthritis disease severity, age, gender, restriction of movement caused by the disease, pain intensity and type of facilities available for these patients and their depression was assessed and it was observed these disease-related factors are associated with depression in these patients.

Also Jamshidi et al., in study on 2016 showed that The prevalence of depression was $63.6 \%$ and anxiety was in $84.1 \%$ among RA patients in Iran and Functional disability was significantly associated with severity of depressive. They stressed the impact of depressive and anxiety symptoms in functional disability and pain perception of RA patients.

There results near our result because in both study prevalence of depression was more than half pf patients. However, in the present study age, gender and marital status variable have no significant relationship with depression in patients. The data of this study indicates that since the prevalence of depression has the highest prevalence in patients with diploma, blue-collar jobs and those who live in rural areas, it is important to care about the importance of psychological training on quality of life and ways to deal with depression in chronic diseases among these communities to reduce depression in patients by increasing awareness and improve the quality of life of these patients. Finally it is proposed to conduct this study in different urban and rural communities with higher sample size and more qualitative and quantitative variables so that by obtaining more data on these patients more powerful decisions are made about these patients. 


\section{References}

Abid rahmani, A., Ghorbanshiroudi, S., Kalatbari, J., Hajiabbasi, A. 2013. Survey of Depression and Anxiety in Patients with Rheumatoid Arthritis, 22(85):15-22.

Ahmet Isik, Suleyman serdar koca. 2007. Anxiety and depression in patients with rheumatoid arthritis. Clin. Rheumatol., 26: 872-878.

Ang, D., H. Choi, K. Kroenke and F. Wolfe. 2005. "Comorbid depression is an independent risk factor for mortality in patients with rheumatoid arthritis," $J$. Rheumatol., vol. 32, pp.,1019 1013 .

Antony, D., Woolf, P.F., Bruce, P.F. 2003. Burden of Major Musculoskeletal Conditions. Bull. World Health Organization, 81(9): 646-656.

Arnow, A.B., Blasely, C.M., Janele Lee, Fireman, B., Hunkeler, E.M., Dea, R., Robinson, R., Hayward, C. 2009. Relationships Among Depression, Chronic Pain, Chronic Disabling Pain, and Medical Costs. Psychiatr. serv., 60(3): 344-50.

Bern Lowe, Levek Willand, Wolfgang Eich, Stephan Zipfel, Anthony D, Wolfgang Herzog, Christoph Fiehn. Psychiatric Comorbidity and Work Disability in Patients with Inflammatory Rheumatic Diseases. Psychosomatic Med., 66: 395-402.

Bern Lowe, Levek Willand, Wolfgang Eich, Stephan Zipfel, Anthony D, Wolfgang Herzog, Christoph Fiehn. Psychiatric Comorbidity and Work Disability in Patients with Inflammatory Rheumatic Diseases. Psychosomatic Med., 66: 395-402.

Cadena, Jose, M., Vinaccias Stefano, M., Pcrez., Adriana, P., et al. 2003. "The Impact of disease activeity on the quality of life, Mental and family,Dysfunction in Colombian patients with Rheumatoid". Arthritis $J$. Clin. Rheumatol., 9(3): 142-150.

Covic Tanya, Cumming Steven, R., et al. 2012. Depression and Anxiety in Patients with Rheumatoid Arthritis: Prevalence rates based on a comparison of the Depression, Anxiety and Stress Scale (DASS) and the Hospital, Anxiety and Depression Scale (HADS). BMC Psychiatry, 12: 6.

Covic, T., Tyson, G., Spencer, D., et al. 2006. Depression in rheumatoid arthritis patients: Demographic, clinical, and psychological predictors. J. Psychosom. Res., 60: 469-476.

de Vries, E., Schipperijn, A.J., Breedveld, F.C. 1994. Antinuclear antibodies in psychiatric patients. Acta Psychiatr. Scand., 89(4): 289-290.

Dunn, A.J., Wang, J., Ando, T. 1999. Effects of cytokines on cerebral neurotransmission. Comparison with the effects of stress. In: Dantzer R, Wollman EE, Yirmiya R (eds) Cytokines, stress and depression. Academic/Plenum, New York, pp 117-127.

Edward, D., Harris, J.R., Gary, S. Firestein. 2009. Clinical Feature of Rheumatoid Arthritis. In: Gray S Firestein, Ralph C Budd, Edward D Harris, Iain B McInnes, Shaun Ruddy, John S Sergent. Kelley's Text book of Rheumatology. 8th Edition. Philadelphia; SAUNDERS ELSEVIER, 1087-1118.

Fereydoun Davachi, Ahmad-Reza Jamshidi, Arash Tehrani Banihashemi. et al. 2008. WHOILAR COCORD Study (stage 1, urban study) in Iran. J. Rheu., 7: 1384-1390.

Fereydoun Davachi, Arash Tehrani Banihashemi, et al. 2009. The Prevalence of Musculoskeletal Complaints in a Rural Area in Iran: a 
WHO-ILAR Copcord Study (stage 1, rural study) in Iran, J. Rheu., 28-12671274.

Jakobsson., ulfrn., Hallberg., Rahm. 2002. "pain and quality of life among older people with Rheumatoid arthritis/or osteoarthritis" J. Clin. Nursing, 11(4): 430- 443.

Jamshidi, A.R., Banihashemi, A.T., Paragomi, P., Hasanzadeh, M., Barghamdi, M., Ghoroghi, S. 2016. Anxiety and depression in rheumatoid arthritis: an epidemiologic survey and investigation of clinical correlates in Iranian population. Rheumatol. Int., 18: $1-7$.

Jiang, X.G., Lin, Y., Li, Y.S. 2014. Correlative study on risk factors of depression among acute stroke patients, 18(9): 1315-23.

Joyce, A.T., P. Smith, R., Khandker, J.M. Melin, A. Singh. 2009. "Hidden cost of rheumatoid arthritis (RA): estimating cost of comorbid cardiovascular disease and depression among patients with RA," $J$. Rheumatol., vol. 36, pp. 743-752.

Liu, Y., HO, R.C., Mak, A. 2012. The role of interleukin (IL)-17 in anxiety and depression of patients with rheumatoid arthritis. Int. J. Rheumatic Dis., 15(2): 183-7.

Lowe, B., L. Willand, W. Eich, S. Zipfel, A.D. Ho, W. Herzog and C. Fiehn. "Psychiatric comorbidity and work disability in patients with inflammatory rheumatic diseases," Psychosom. Med., vol. 66, pp. 395402.

Maes, M., Meltzer, H., Bosmans, E., Bergmans, R., Vandoolaeghe, E., Rajan, R. et al. 1995. Increased plasma concentrations of interleukin6, soluble interleukin-6 receptor, soluble interleukin-2 receptor and transferrin receptor in major depression. J. Affect. Disord., 34: 301309.

Malemud, C.J., Miller, A.H. 2008. Proinflammatory cytokine-induced SAPK/MAPK and JAK/STAT in rheumatoid arthritis and the new antidepression drugs. Expert opinion on therapeutic targets, 12(2): 171-83.

Maloes, M.J.G., Gerrits, Nicole, Vogelzangs, Patricia Van Oppen, Harm, W.J. Van Marwijk, Henriette, Van Der Host, Brenda, W.J.H. Penninx. Impact of Pain on the Course of Depressive and Anxiety Disorders. J. Pain, 1: 1-7.

Margaretten Mary, Julian Laura, et al. 2011. Depression in patients with rheumatoid arthritis: description, causes and mechanisms. Int. J. Clin. Rheumtol., 6(6): 617-623.

Mella, L.F., Bértolo, M.B., Dalgalarrondo, P. 2010. Depressive symptoms in rheumatoid arthritis. Revista Brasileira de Psiquiatria, 32(3): 25763.

Nayak Rajesh, Rajpura Jigar. 2013. Assessing Depression among Older Persons with Arthritis: A Nationwide Health Status Survey. Hindawi Publishing Corporation, Volume 2013, Article ID 968343, 7 pages.

Neal Robert, W. 2009. Psychosocial Management of Rheumatic Diseases. In: Gray S Firestein, Ralph C Budd, Edward D Harris, Iain B McInnes, Shaun Ruddy, John S Sergent. Kelley's Text book of Rheumatology. 8th Edition. Philadelphia; SAUNDERS ELSEVIER, 999-1007.

Razavian, F., abbasi, M., kazemnejad, A. 2009. The Relationship between Depression and the Quality of Life in Patients with Rheumatoid Arthritis, 16(80): 27-34.

Saba Mousavi, Sanath Chattergi, Emese Verdes, Ajaya Tandon, Bedirhan 
Ustun. Depression, Chronic Diseases, and Decrements in Health: Results from the World Health Survey. Lancet, 370: 851-858.

Scherrer, J.F., K.S. Virgo, A. Zeringue, K.K. Bucholz, T. Jacob, R.G. Johnson, W.R. True, R. M. Carney, K.E. Freedland, H., Xian, L. Caplan, J. 2009. McDonald and S. A. Eisen, "Depression increases risk of incident myocardial infarction among Veterans Administration patients with rheumatoid arthritis," Gen. Hosp. Psychiatry, vol. 31, pp359-353 .

Simcha, M., Russak, J., Croft, J., et al. 2003. The use of rheumatoid arthritis healthrelated quality of life patient questionnaires in clinical practice: losson learned. Arthritis \& Rheumatism (Arthritis care \& Research), 49(4): 574-584.

Tillmann Taavi, Krishnadas Rajeev, et al. 2013. Possible rheumatoid arthritis subtypes in terms of rheumatoid factor, depression, diagnostic delay and emotional expression: an exploratory case-control study. Arthritis Res. Ther., 15: R45.

Travis, O., Bruce. 2008. Comorbid Depression in Rheumatoid Arthritis: Pathophysiology and Clinical Implications. Curr. Psychiatry Reports, 10: 258-264.

Van lankveld, W., Naring, G., Van Pad, Bosch, P., Van de Putte, L. 2003. Strees caused by rheumatoid arthritis: relation among subjective stressors of the disease, disease status and wellbeing. J. Behavioral Med., 16(3): 309321.

Venables, P.J.W., R.N. Maini. 2011. Clinical Features of Rheumatoid Arthritis.[Serial online]. [24 Screen]. Available From:ULR: www.Uptodate.com

Wolfe F., \& Hawley D.J. 2000. Measurement of the quality of life in rheumatic disorder using the Euro Qol". British J. Rheumatol., 36(7): 789-793.

\section{How to cite this article:}

Masoumeh Nazarinasab, Sirous Pakseresht, Elham Rajai and Soroush Saneifard. 2016. Depression in Patients with Rheumatoid Arthritis and its Relationship with Clinical and Demographic Variables in Golestan Hospital of Ahvaz, Iran. Int.J.Curr.Res.Aca.Rev.4(10):112. doi: http://dx.doi.org/10.20546/ijcrar.2016.410.001 